\title{
Austrian universities come under scrutiny...
}

Munich. Austria's biomedical research community has come in for harsh criticism in a report by an international review committee, commissioned by the Austrian Biochemical Society and presented to the ministry of science and research last week.

The report says that the standard of biomedical research in Austria is, on average, well below that of other European countries of similar size and wealth, such as Sweden, the Netherlands and Switzerland. It puts most of the blame on Austria's universities, where most such research is carried out and which can give tenure to scientists without requiring proof of research competence.

The review committee, chaired by Fritz Paltauf, a biochemist at the Technical University in Graz, was organized by the European Molecular Biology Organization. It says that while several centres carry out "excellent work", the scientific output of many research groups is poor, and criticizes an apparent lack of concern in the academic world that such groups are still funded.

The prime cause of this poor performance, according to the report, is Austria's "misguided" policy for academic appointments, which has had a "devastating" effect on many institutes. Tenured positions are too often made on non-scientific criteria such as age. The review panel claims this blocks opportunities for ambitious young researchers, already hampered by a law preventing temporary appointments for professors and assistant professors.

University traditions also leave the research community split up into groups that are too small to compete international-

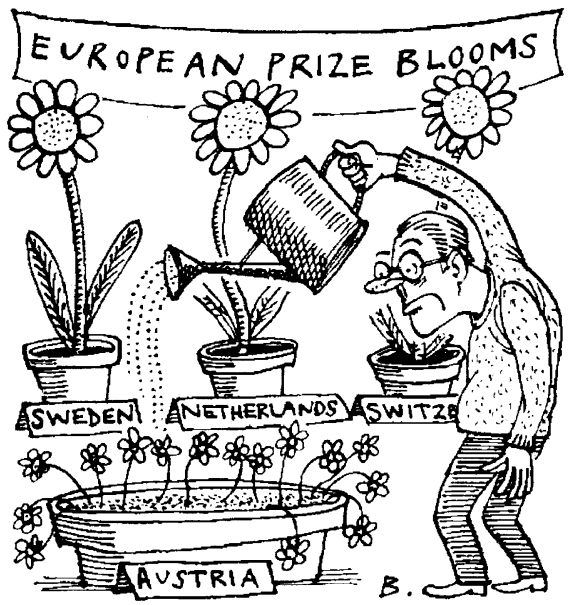

ly. The panel does not criticize the level of research funding. But it points out that the money tends to be spread among too many groups rather than being concentrated on the stronger ones.

A top priority, says the review panel, is that universities should be required to evaluate the research competence of scientists being offered tenure. It also recommends that grant applications be assessed more critically, with larger grants given to strong research groups. "largely agrees" with the report's conclusions, but blames the absence of non-university research institutes in Austria, in addition to university procedures, for its failings in biomedical research.

But the problems identified by the review panel are not confined to biomedical research. Austria's 18 universities, traditionally tightly controlled by the science and research ministry in Vienna, are attempting to implement a new law, passed in 1993, that gives them extensive administrative and financial autonomy.

The law requires that procedures be set up to ensure that successful researchers are allocated an appropriate proportion of university resources. But the implementation of these procedures remains slow in the face of considerable resistance from the universities. Meanwhile, a further draft law, drawn up by the research ministry to allow temporary positions for professors, continues to meet political opposition, particularly from trades unions.

Helmut Ruis, a professor of biochemistry
The Austrian Biochemical Society says it

at the University of Vienna's Biozentrum who has long argued for a more selective distribution of research money and is a driving force behind the setting up of the review panel, says he hopes that its conclusions will help to convince the government it must address the university system's shortcomings.

Outside the universities, however, there are some encouraging signs of change. Most public funds for basic research are distributed through the national agency, the Fonds zur der Förderung der Wissenschaftlichen Forschung (FWF). This has long been criticized as operating on the 'Gießkanne' or 'sprinkler' principle, with research money distributed to weak and strong alike in 'drops' too small to be effective.

This year, however, the FWF has raised its rejection rate for grant applications from 25 per cent to 40 per cent, and the length of grants from two to three years. The agency has also just launched a programme giving young scientists five years of generous funding, averaging ÖS 2.5 million (US $\$ 240,000$ ) per year, to set up independent their own research groups. Ten scientists will be funded in this way each year.

Alison Abbott

\section{... as Japan backs fixed-term posts}

Tokyo. In a significant break with tradition, Japan appears poised to take its first tentative step towards introducing limited-term appointments - rather than lifetime employment - for university staff.

The change has been recommended in the interim report of a committee set up by the University Council, an advisory body to the Ministry of Education, Science, Sports and Culture (Monbusho). It is aimed at encouraging better research and teaching, and could eventually lead to a radical reform of the whole university system.

Winning acceptance of the idea of limited term appointments "took a long time to achieve", says Akito Arima, vice-president of the council. Arima is president of the Institute of Physical and Chemical Research (RIKEN), as well as a former president of Tokyo University, and headed the council committee responsible for writing the interim report.

Nevertheless, Arima admits that he wanted "a more decisive decision" at this stage on the reform of employment practices, and says he still sees a long road ahead before the changes recommended in the report to be followed by a more substantial final report in about a year - are implemented.

Reflecting conflicting views in the council itself, the report suggests that individual universities should be allowed to decide whether to introduce limited-term appointments, to set their duration and to specify the conditions under which they can be renewed. As such, the recommendations are "very weak", admits Arima, who has been campaigning vigorously for years for reform of Japan's university system.

Along with limited-term appointments, the council recommends a system of assessing university staff that would operate before a contract is renewed. The report gives no details of how such assessments should be carried out, or how the results should be applied. But it would include an assessment both of teaching - possibly by students - and of research output.

Introducing limited-term appointments will make it necessary to rewrite Japan's labour laws. These stipulate that government employees, including national university staff, can be employed only on a permanent basis. "My main aim is to change the law," says Arima. He points out that a university could at present be successfully sued for trying to dismiss a member of staff.

Some universities have already managed to reach agreement with some staff to limit the length of appointments. At Kyoto University's Research Institute for Fundamental Physics, for example, full and associate professors are usually limited to terms of 5 to 10 years, and research assistants to 3 to 6 years under an informal 'gentleman's agreement'. Changing the law would put such a system on firm legal footing.

But the new law could not be applied 
retroactively. All existing university staff would therefore retain the right to lifetime employment. Unsurprisingly, therefore, most senior university staff support the councils' recommendations, while many young researchers who have been waiting in line for permanent positions - often for years - are opposed to them.

To ease the situation of young researchers, the coalition government has, at Arima's urging, agreed to increase the number of postdoctoral fellows in Japan from the present level of 4,000 to 10,000 by the year 2000. That will help the many socalled 'over-doctors' (a Japanese term derived from English) who have PhDs but no permanent post and who continue doing research by supporting themselves with parttime jobs.

To pay for this, both Monbusho and the Science and Technology Agency have applied for extra funds next fiscal year (which begins on 1 April), and Monbusho plans to boost the salary for fellowships from $¥ 280,000(\$ 2,800)$ to $¥ 400,000$ a month to make them more attractive.

At the same time, Arima is urging the Japanese government to stop employing young scientists as research assistants, a position that provides lifetime employment. Instead, he would like it to appoint technicians to such posts, thereby helping to ease the chronic shortage of technical staff in universities. He hopes this policy will be adopted next year, "provided that they [young researchers] don't kill me first".

David Swinbanks

\section{Europe to strengthen links on marine and polar projects}

Paris. Scientists from 30 institutes in 17 European countries have agreed to set up two new bodies aimed at improving the coordination of marine and polar research in Europe. The European boards for marine and polar science, as they are known, will be established under the auspices of the European Science Foundation (ESF), based in Strasbourg, France. Each will have 20 members, overseen by a joint executive committee, and will be administered from the ESF.

The marine science board will be chaired by Daniel Cadet, deputy director of the Institut des Sciences de l'Univers of the Centre National de la Recherche Scientifique (CNRS). Barry Heywood, director of the British Antarctic Survey, will chair both the polar sciences board and the executive committee overseeing the two boards.

According to Heywood, the reason for setting up the boards, agreed at a meeting in Paris last week, is the need "to find quick answers to very important scientific problems at a time when budget resources are shrinking and research equipment is getting more expensive".

To achieve this, the meeting concluded that Europe needs large programmes lasting at least ten years, and costing more than ECU50 million (US\$61 million). Until now,

\section{Paris pendulum swings back into action}

\begin{abstract}
Paris. France's annual science festival - Science en Fête got off to a swinging start last week when the original Foucault pendulum (right) oscillated under the majestic dome of the national mausoleum, the Panthéon, for the first time since Léon Foucault used it to demonstrate Galileo's theory that the Earth turns on its axis.

Foucault's original pendulum bob - a brass-plated lead ball, $38 \mathrm{~cm}$ in diameter, weighing 28 kg - was taken from its home
\end{abstract} in the Conservatoire National des Arts et Métiers for the reconstruction. It was attached to the apex of the Panthéon dome, 67 metres above the ground, by a steel cable, and after its release by François Bayrou, France's Minister of Education, soared back and forth across the Panthéon, taking 16.5 seconds to complete each swing.

The science festival, which this year includes more than 1,800 scientific events, is unlikely to create

\section{IMAGE UNAVAILABLE FOR COPYRIGHT REASONS}

the same stir as Foucault's first demonstration of his pendulum, which proved an immediate success with the public and was subsequently reproduced in many other cities. Recognition of Foucault - an autodidact who also invented the gyroscope - by the scientific community took longer; he was admitted to the French Academy of Sciences only in 1865 , three years before his death. most marine and polar programmes in Europe have tended to be national programmes lasting between one and three years, and the large programmes identified could not be afforded by one nation alone.

The first programme for which the boards will seek support is on climate change, the European Project for Ice Coring in the Antarctica (EPICA). Estimated to cost ECU50-ECU60 million, this will investigate whether the findings of ESF's Greenland Icecore Project (GRIP) - that the Earth's climate has been stable for around 10,000 years, but fluctuated violently before that - are a regional or global phenomena.

Other so-called 'grand challenges' identified at the meeting include a programme forecasting physical, chemical and biological processes in oceans and coastal seas over timescales ranging from seasons to decades, a project to map the Arctic Ocean and a study of the deep sea floor.

Half the funding for such programmes would come from European Union (EU) research funds, in particular, the Marine Science and Technology (MAST) programme - which has a budget of ECU228 million for the period 1994-98 - and environment programmes. The other half would come from national research agencies.

Proposals for EU funding would be required to compete with other bids under standard research grant procedures. Nevertheless, the European Commission, which has been involved in the creation of the boards from the outset, is enthusiastic about the prospect of large cooperative programmes. "The scientists took this initiative, and we are keen to support them," says one commission official.

Heywood says the boards are willing to tailor proposals to the commission's requirements, pointing out that many of the boards' members are also members of the programme committees. But he emphasizes that the boards will proceed modestly. "We want to be pragmatic", he says, with each national group first identifying its own interests and then discussing possible collaboration with others. The boards' role will be primarily to implement agreed projects, he says, not to act as a talking shop. "We need to obtain street credibility, in particular with national governments.'

One aim of the boards will be to seek better use of Europe's existing research fleet of 20 large vessels, as well as costly facilities such as submersibles and satellites. Ultimately their goal is to provide Europe with a single voice for marine and polar science in negotiations with the European Commission and other international bodies.

Declan Butler 